\title{
Up-regulation of BRCA1 and Rad51 Genes Expression in Peripheral Blood Mononuclear Cells is Associated with Hepatitis B Patients
}

\section{Arghavan Asghari}

Student Research Committee, Birjand University of Medical Sciences

\section{Seyed Rezae}

Microbiology Department, Virology Division, Mashhad University of Medical Sciences, Mashhad,

\section{Masood Ziaee}

Infectious Diseases Research Center, Birjand University of Medical Sciences

\section{Narges Valizadeh}

Immunology Research Center, School of Medicine, Mashhad University of Medical Sciences, Mashhad

\section{Davod Javanmard}

Infectious Diseases Research Center, Birjand University of Medical Sciences

\section{Mohsen Naseri ( $\nabla$ Naseri_m2003@yahoo.com )}

Cellular and Molecular Research Center, Genomic Research Group, Birjand University of Medical

Sciences, Birjand

\section{Research Article}

Keywords: BRCA1, HBV, Homologous Recombination, Rad51

Posted Date: January 5th, 2021

DOl: https://doi.org/10.21203/rs.3.rs-132587/v1

License: (c) (1) This work is licensed under a Creative Commons Attribution 4.0 International License.

Read Full License 


\title{
Up-regulation of BRCA1 and Rad51 genes expression in peripheral blood mononuclear cells is associated with hepatitis B patients
}

\author{
Arghavan Asghari ${ }^{1,2}$, Seyed Abdolrahim Rezae ${ }^{4}$, Masood Ziaee ${ }^{1}$, Narges Valizadeh ${ }^{5}$, Davod \\ Javanmard ${ }^{1}$, Mohsen Naseri ${ }^{3 *}$
}

1. Infectious Diseases Research Center, Birjand University of Medical Sciences, Birjand, Iran.

2. Student Research Committee, Birjand University of Medical Sciences, Birjand, Iran.

3. Cellular and Molecular Research Center, Genomic Research Group, Birjand University of Medical Sciences, Birjand, Iran.

4. Microbiology Department, Virology Division, Mashhad University of Medical Sciences, Mashhad, Iran.

5. Immunology Research Center, School of Medicine, Mashhad University of Medical Sciences, Mashhad, Iran.

\section{*Corresponding author:}

Mohsen Naseri, Cellular and Molecular Research Center, Birjand University of Medical Sciences, Birjand, Iran. Tel: +98-5632395450, Fax: +98-5632381119, Postal code: 9717853577, E-mail: Naseri_m2003@yahoo.com, ORCID ID:0000-0003-3100-6344 


\section{Abstract}

Background: Many viruses increase their replication by affecting DNA damage response (DDR) signaling and activating and inhibiting DNA damage response factors. to date, few studies have investigated Homologous Recombination (HR) system in the field of hepatitis B patients. The current study set out to investigate HR system by examining the expression of RAD51, BRCA1, and HBx genes in peripheral blood mononuclear cells (PBMCs) of hepatitis B patients. Two groups of subjects were enrolled including healthy controls $(n=61)$ and hepatitis B patients $(n=60)$. The serum levels of HBV DNA, Rad5 1and BRCA1, in the PBMCs were measured using real-time quantitative polymerase chain reaction (PCR.) Moreover, serum levels of liver enzymes (ALT and AST) levels were assessed by automatic biochemical analyzer technique.

Results: In HBV-infected patients, the gene expression of Rad51 and BRCA 1 were significantly upregulated compared to healthy controls $(\mathrm{P}<0.05)$. However, There is a statistically significant correlation between $\operatorname{Rad} 51(\mathrm{r}=0.838$; $\mathrm{P}$ value $<0.001)$ and $\mathrm{BRCA} 1(\mathrm{r}=$ $0.588 ; \mathrm{P}$ value $<0.05)$, genes expression and viral load.

Conclusions: These results demonstrated that hepatitis B virus affected the homologous recombination system by increasing the expression of Rad51 and BRCA1 genes, suggesting these genes could be considered as valuable therapeutic targets for treating hepatitis B patients.

Keywords: BRCA1, HBV, Homologous Recombination, Rad51. 


\section{Background}

Hepatitis B virus (HBV) is one of the enveloped viruses with DNA genetic structure. Infection with this virus is one of the global problems [1]. According to studies, one-third of the world's population is affected by this virus, of which $5 \%$ are carriers. $25 \%$ of carriers suffer from chronic hepatitis and cirrhosis of the liver, and eventually from hepatocarcinoma (HCC). Previous studies show that despite the vaccination against hepatitis B and available treatments, an average of 780,000 people dies each year from the disease $[2,3]$.

One of the main causes of HCC can be the presence of hepatitis B virus DNA in the serum of people with chronic hepatitis B (CHB) infection [4]. The severity of hepatocarcinoma is related to the degree of viral load [5]. In general, the HBV virus causes HCC through two mechanisms; first, by inserting a viral genome into the host genome structure, and removing cancer-inhibiting genes, which leading to DNA damages. As a result, instability in the host genome has occurred, resulting in cancer progression. Second, by disrupting cellular signaling pathways, which in turn can disrupt the cell cycle, eventually leading to cell proliferation and cancer development [6]. Earlier studies demonstrated that Protein $\mathrm{x}$ in hepatitis B (HBx) 154 amino acids and N-terminal region with negative regulatory properties and having $\mathrm{C}$-terminal region with its transactivator properties has a dual play key role in the pathogenesis of hepatocarcinoma. It causes malignancies caused by viral infections in host liver cells [7]. HBx protein does not directly increase the expression of target genes, however, it effects by acting on the promoter and enhancers of the target genes [8]. $\mathrm{HBx}$ affects various signaling pathways, including reactive oxygen species (ROS), apoptosis and cellular growth, Ras-Raf-MAP kinase pathway, transforming growth factor- $\beta$, Tumor narcosis factor, Wnt/catenin signaling, cell, chromosomal division, and DNA repair, which can eventually lead to disease progression and hepatocarcinoma [9-12].

Many viruses increase their replication by affecting DNA damage response (DDR) signaling and activating and inhibiting DNA damage response factors [13]. HBV affects the DNA repair system and DDR in various dimensions. In a study conducted by Su Jeong Kim et al., they found that $\gamma$ H2AX, a marker of double-stranded DNA breaks (DSBs), and phospho-Chk2 rates were

considerably greater in HCC associated with HBV and neighboring restoring nodules [14]. Many studies have found HBx attaches to DNA binding protein 1 like $\mathrm{X}$-associated protein 1 (XAP-1) and UV-damaged DNA-binding protein (UVDDB). It has been revealed that interaction is necessary for HBV replication $[15,16]$. A great deal of previous research has also shown that $\mathrm{HBx}$ 
could impact on the nucleotide excision repair system by interacting with key proteins such as TFIIH, XPD, and XPB [17, 18]. Also, HBx protein interacts with the DNA glycosylase enzyme thymine to affect the Base Excision Repair (BER) system [19].

In studies on oncogene viruses such as HPV, KSV, HTLV1, etc. [20], they can increase the pathogenicity of viral infections by affecting another DNA repair system called the homologous repair (HR) pathway. Important members of this system include BRCA1 and Rad51. BRCA1 plays a key role in genome stability. This protein, known as an assembly protein, interacts with other cellular proteins. This protein has a role in DNA repair, cell cycle progression, and gene transcription [21]. Rad51 is an important member in repairing double-stranded DNA breaks by homologous recombination method. Throughout the recombination process, Rad51 attaches transiently to both single-strand and double-strand DNA [22].

Since studies have shown that HBV virus can replicate pbmcs causing disruption of gene expression in the host $[23,24]$ to date, few studies have investigated homologous recombination system in the field of HBV. Therefore, this study set to investigate the gene expression of the two main factors of this system including BRCA1 and Rad51.

\section{Method}

\section{Study design}

This study was approved by the Birjand University of Medical Sciences (BUMS) (No: 455976). Patients with hepatitis B are referred to us in the Center for Infectious Diseases and the Eastern Hepatitis Network. all methods were performed in accordance with the relevant guidelines and regulations.

\section{Blood sample collection}

After obtaining informed consent from the introduced individuals, blood samples were collected from patients and controls.

\section{Laboratory testing}

All samples were investigated for Anti-HBc, (anti-HBc, Biokit, Barcelona, SpainHBs antigen (HBsAg, Dade Behring, Germany), anti-HDV (Biokit, Barcelona, Spain), and anti-HCV (HCV Antibody ELISA kit, Pishtazteb, Iran) using ELISA kits, according to manufactures instrument. 


\section{Sample selection}

Samples with HBs positive were considered as patients with hepatitis B, and those with negative $\mathrm{HBc}$ and negative HBs were considered as the control group. Anti-HDV and anti-HCV were negative in the study samples, and they did not take any special medicine. Finally, 60 patients and 61 control subjects were selected for analysis, and the enzymatic levels of aminotransferase and aspartate aminotransferase were evaluated in patients using an automatic biochemical analyzer (Beckman Coulter, Inc., Brea, CA, USA).

\section{HBV Viral Load Analysis}

All patients were evaluated for viral loading of HBV using cobas® 4800 System (Roch-USA).

\section{RNA extraction and reverse transcription (RT) quantitative PCR detection}

Whole-blood samples were extracted from patients and controls, then peripheral mononuclear blood cells (PBMCs) were separated by Ficoll density gradient (inno-trian, Germany) from EDTAtreated blood samples.

Complete extraction of RNA from PBMCs was carried out using the wizol reagents (wizbio Solutions-South Korea) to purify total RNA, according to the manufacturer's guidance. Before analysis, the extracted RNA was held at $-70{ }^{\circ} \mathrm{C}$. The integrity of RNA was evaluated by $1 \%$ modified electrophoresis of the agarose gel and the RNA. The detection of density and purity of total RNA was performed using NanoDrop ((NanoDrop 8000 spectrophotometer, Thermo Fisher Scientific, Wilmington, Delaware). Two micrograms of total RNA were reversed to cDNA via random hexameric primers and cDNA synthesis package RevertAid ${ }^{\mathrm{TM}}$ First-Strand (Glen Burnie, MD, Fermentas, USA). Using the PCR technique for the internal GPDH gene to assess the quality of cDNA synthesis then $1.5 \%$ agarose gel was used to analyze post-PCR products to confirm the amplification

The BRCA1, Rad51, and HBx expression patterns were tested with real-time PCR assay by the sybr green method (Table 1). The expression level of each target gene was doubled and normalized to the level of human expression of beta-2-microglobulin, as a reference gene. PCR was utilized in real-time using an ABI Step One Plus Sequence Detection Method 2.1 (Applied Biosystem, USA). Ultimately, about the related effectiveness of different qPCR assays, the $-\Delta \Delta C t$ method formula was used to assess the relative rates of gene expression.

\section{Statistical analysis}


Statistically, the study results are described as mean \pm SEM. SPSS program ver.13.0 (SPSS, Chicago, IL, USA) did data analysis. To check the normality of the data, we use the KolmogorovSmirnovt est. If the data is normal, we use parametric tests and if the data is not normal, we use non-parametric tests

\section{Results}

\section{Demographic characteristics}

One hundred and twenty-one participants (64 males and 47 females) with an average age of 38.4 \pm 18.7 years old were included in the study. Among them, 60 patients (39 males and 21 females) with an average age of $38.4 \pm 16.8$ years old were included in the study. The mean HBV-DNA was $1.449 \pm 5.738 \mathrm{ng} / \mathrm{ml}$. AST $38.30 \pm 28.27$, and ALT 19.567 \pm 13.2527 IU/L. In 54 cases, HBeAg was negative, and in 6 cases, $\mathrm{HBeAg}$ was positive (Table 2). In the control group, sixty-one samples ( 25 males and 26 females) with an average age of $32.9 \pm 19.7$ years old were included in the study. AST $26.5 \pm 9.11$, and ALT 14.9 $\pm 6.3 \mathrm{IU} / \mathrm{L}$.

\section{mRNA Expression of Rad51 and BRCA1}

Homologous recombination is one of the DNA repair pathways. One of the important components of this system is Rad51. This protein reacts with RPA and Rad52 to induce strand transfer of DNA. This protein also reacts with BRCA1 due to double-strand breaks [25]. BRCA1 plays an important role in maintaining the integrity of the genome and induces DNA restorative signaling through the homologous DNA repair system [26].

To determine the possible roles of Rad51 and BRCA1 in the pathogenesis of hepatitis B, the mRNA expression levels of Rad51and BRCA1 were measured and results can be seen in Figures $1 \& 2$. Rad51and BRCA1 gene expression were significantly up-regulated in hepatitis B patients compared to healthy controls ( $P<0.01$ and $P<0.05$, respectively). There is a positive significant correlation between Rad51and viral load ( $\mathrm{r}=0.83 ; \quad P=0.0004)$. Moreover, a positive significant correlation was found between BRCA1 gene expression and viral load $(\mathrm{r}=0.58 ; P=0.029)$ (Table $3)$. 


\section{Discussion}

Today, it is one of the most popular novels for the treatment of cancer. It targets the signaling pathways of DNA repair. Defects or overexpression of unique pathways that recognize or repair specific types of DNA damage may serve as biological markers with a favorable or poor response to therapies that cause DNA damage of this kind [27]. One of the DNA repair pathways that has recently been considered in the treatment of cancer is the HR system. Among the important components of this system, BRCA1 and Rad51 can be mentioned[28]. Upregulation of Rad51 protein in cancer ls has been proven to increase radioresistance of cancer cells [29] In certain cancers, high Rad51 expression is correlated with an adverse prognosis in tumor tissue [30, 31] According to studies, Rad51 can be considered as one of the main goals of cancer treatment [32, 33]. BRCA1 with 1800 amino acids plays a special role in DNA repair, Cell proliferation and Regulation of transcription[34]. Changes in the expression of this protein factor can lead to the progression of cancer and the cause of cancer, and can also affect the treatment options based on this factor $[27,35,36]$.

Despite many advances in treating and preventing people from being infected with the hepatitis B virus, we also observe the spread of the disease and the chronicity of the disease in people and the development of hepatocarcinoma in infected people [37]. Hepatocarcinoma is the sixth most common cancer in general, but the third most prevalent cause of cancer death $(24,25)$. New studies show that more than 50 percent of people who get hepatocellular carcinoma are infected with the hepatitis B virus [38, 39]

Viruses cause $20 \%$ of cancers in humans [40]. Oncogenic DNA viruses cause cancer in a variety of ways, one of the most important of which is disrupting the host genome structure by inserting it into the host cell DNA or disrupting the host's genetic repair system [41]. Studies have shown that DNA damage and chromosomal abnormalities due to chronic inflammation have a special role in causing hepatocarcinoma [42]. There are many studies on the effect of hepatitis B virus on DNA repair systems such as NER and BER repair systems [17, 18], but few studies have been performed on homologs recombination system. Many studies on other viruses with the dsDNA genetic structure have shown that these viruses cause the virus to be located in the host genome and also prevent cell apoptosis by increasing the expression of the two major factors of the homologs recombination, Rad51 and BRCA1. Our study also confirms this evidence for the hepatitis B virus 
[43-45]. By increasing the expression of these two factors, the virus appears to inhibit apoptosis due to genetic instability of the host and cause it to spread in the host [46].

In a study by Yan Liao et al. on hepatocarcinoma, a complex called BRCA1associated RING Domain 1 (BARD1) was found to be highly expressed in this cancer, which causes cancer cells to invade, proliferate, and migrate. The high expression of this complex has been introduced as a predictive biomarker for the progression of the disease. They also found examining the HBs antigen of the participants, a significant relationship between people infected with the hepatitis B virus and the expression of this complex, which is also consistent with our data [47].

According to the data obtained from this study and other available studies, two factors, BRCA1 and $\operatorname{Rad51,~can~be~considered~as~biomarkers~to~study~the~disease~process.~Therefore,~BRCA1plays~}$ a major role in HBV-related HCC tumorigenesis and may serve as a new molecular targeted

therapy for further clinical practice. Tumor DNA repair failure has been a treatment option in oncology for over a century, as demonstrated by the broad use of chemotherapy drugs that destroy DNA and ionize radiation [48].

In the current study, we tried to prevent interfering factors such as viral disease, the effect of drugs, and underlying diseases that affect the study process and to get more reliable results; this led to a small number of samples to be studied

\section{Conclusion}

Rad51 and BRCA1 were found to have significantly higher gene expression in people with hepatitis B than healthy controls. However, the current study requires to be further investigation with a larger sample size to confirm the findings. HBx expression was seen in only three samples, assessing the relationship between the effect of this oncoprotein HBx and the expression of Rad51 and BRCA1 is required.

\section{List of abbreviations}

HBV: Hepatitis B virus

HCC: hepatocarcinoma

CHB: chronic hepatitis B

HBx: Protein $\mathrm{x}$ in hepatitis B 
BRCA1: breast cancer gene 1

XAP-1: X-associated protein 1

UVDDB: UV-damaged DNA-binding protein

BER: Base Excision Repair

DDR: DNA damage response

DSBs: double-stranded DNA breaks

HR: homologous repair

\section{Declaration section}

\section{Ethics approval and consent to participate}

The study was approved by the Ethics Committee of the Birjand University of Medical Sciences, Center for Infectious Diseases and the Eastern Hepatitis Network(Ir.bums.REC.1398.236). All methods were performed in accordance with the relevant guidelines and regulations.Written informed consent to take part was obtained from all participants (or their parents or legal guardians in those under 18 years of age) for clinical and genetic investigation.

\section{Consent for publication}

Written informed consent for publication of clinical details was obtained from all of the all participants. (or their parents or legal guardians in those under 18 years of age). A copy is available to the journal if needed.

\section{Availability of data and materials}

The data that support the findings of this study are available from the corresponding author, Mohsen Naseri, upon reasonable request.

\section{Competing interests}

The authors declare no competing interests. 


\section{Funding}

This work was supported through funding from the Birjand University of Medical (grant number:455976). Mashhad University of Medical Sciences provided us with RNA extraction kits and primers related to the study genes(grant number: 980930).

\section{Authors' contributions}

M.N was responsible for overall supervision. A. A, N.V and D.J Participated in study design, conducted molecular experiments and PCR analysis, data collection and evaluation, drafting and statistical analysis. M.Z and S.A.R: They have been involved in collecting samples and introducing hepatitis B patients. A.A and D.J: they were responsible for editing the article. A. A: Participated in study design. All authors read and approved the final manuscript.

\section{Acknowledgements}

This work was supported by Birjand University of Medical Sciences. We thank all clinicians and hospital staff of Infectious Diseases Research Center, Birjand University of Medical Sciences.

\section{Author information}

\section{Affiliations}

Infectious Diseases Research Center, Birjand University of Medical Sciences, Birjand, Iran

Masood zaiee,Davod janamard

Student Research Committee, Birjand University of Medical Sciences, Birjand, Iran.

Arghavan Asghari

Microbiology Department, Virology Division, Mashhad University of Medical Sciences, Mashhad, Iran.

Seyed Abdolrahim Rezae

Immunology Research Center, School of Medicine, Mashhad University of Medical Sciences, Mashhad, Iran.

Narges valizaeh

\section{Corresponding author}


Mohsen Naseri, Cellular and Molecular Research Center, Birjand University of Medical Sciences, Birjand, Iran. Tel: +98-5632395450, Fax: +98-5632381119, Postal code: 9717853577, E-mail: Naseri_m2003@yahoo.com, ORCID ID:0000-0003-3100-6344

\section{References}

1. Trépo C, Chan HL, Lok AJTL: Hepatitis B virus infection. 2014, 384(9959):2053-2063.

2. Magalhães MJ, Pedroto I: Hepatitis B virus inactive carriers: which follow-up strategy? $G E$ Portuguese Journal of Gastroenterology 2015, 22(2):47-51.

3. Trépo C, Chan HLY, Lok A: Hepatitis B virus infection. The Lancet 2014, 384(9959):2053-2063.

4. Lee WY, Bachtiar M, Choo CC, Lee CGJBR: Comprehensive review of $\mathbf{H}$ epatitis BV irusassociated hepatocellular carcinoma research through text mining and big data analytics. 2019, 94(2):353-367.

5. Lemoine M, Thursz MRJJoh: Battlefield against hepatitis B infection and HCC in Africa. 2017, 66(3):645-654.

6. Chaturvedi VK, Singh A, Dubey SK, Hetta HF, John J, Singh MP: Molecular mechanistic insight of hepatitis B virus mediated hepatocellular carcinoma. Microbial Pathogenesis 2019, 128:184194.

7. Muroyama R, Kato N, Yoshida H, Otsuka M, Moriyama M, Wang Y, Shao R-X, Dharel N, Tanaka Y, Ohta MJJoh: Nucleotide change of codon 38 in the $X$ gene of hepatitis $B$ virus genotype $C$ is associated with an increased risk of hepatocellular carcinoma. 2006, 45(6):805-812.

8. Zhang XD, Wang $Y, Y$, $L H$ : Hepatitis $B$ virus $X$ protein accelerates the development of hepatoma. Cancer biology \& medicine 2014, 11(3):182-190.

9. Hsieh A, Kim H-S, Lim S-O, Yu D-Y, Jung GJCl: Hepatitis B viral X protein interacts with tumor suppressor adenomatous polyposis coli to activate $W n t / \beta$-catenin signaling. 2011, 300(2):162172.

10. Cho I-R, Oh M, Koh SS, Malilas W, Srisuttee R, Jhun BH, Pellegrini S, Fuchs SY, Chung Y-HJljomm: Hepatitis $B$ virus $X$ protein inhibits extracellular IFN- $\alpha$-mediated signal transduction by downregulation of type I IFN receptor. 2012, 29(4):581-586.

11. Forgues M, Difilippantonio MJ, Linke SP, Ried T, Nagashima K, Feden J, Valerie K, Fukasawa K, Wang XWJM, biology c: Involvement of Crm1 in hepatitis B virus X protein-induced aberrant centriole replication and abnormal mitotic spindles. 2003, 23(15):5282-5292.

12. Peng Z, Zhang Y, Gu W, Wang Z, Li D, Zhang F, Qiu G, Xie KJljoo: Integration of the hepatitis B virus $X$ fragment in hepatocellular carcinoma and its effects on the expression of multiple molecules: a key to the cell cycle and apoptosis. 2005, 26(2):467-473.

13. Hollingworth R, Grand RJJV: Modulation of DNA damage and repair pathways by human tumour viruses. 2015, 7(5):2542-2591.

14. Kim S, Lee H-S, Ji J-H, Cho M-Y, Yoo Y-S, Park Y-Y, Cha H-J, Lee Y, Kim Y, Cho HJJoGV: Hepatitis B virus $X$ protein activates the ATM-Chk2 pathway and delays cell cycle progression. 2015, 96(8):2242-2251.

15. Lee TH, Elledge SJ, Butel JS: Hepatitis B virus $\mathbf{X}$ protein interacts with a probable cellular DNA repair protein. Journal of virology 1995, 69(2):1107-1114. 
16. Sitterlin D, Lee TH, Prigent S, Tiollais P, Butel JS, Transy C: Interaction of the UV-damaged DNAbinding protein with hepatitis $B$ virus $X$ protein is conserved among mammalian hepadnaviruses and restricted to transactivation-proficient X-insertion mutants. Journal of virology 1997, 71(8):6194-6199.

17. Qadri I, Fatima $\mathrm{K}$, AbdeL-Hafiz $\mathrm{H}$ : Hepatitis $\mathbf{B}$ virus $\mathbf{X}$ protein impedes the DNA repair via its association with transcription factor, TFIIH. BMC Microbiology 2011, 11(1):48.

18. Jaitovich-Groisman I, Benlimame N, Slagle BL, Perez MH, Alpert L, Song DJ, Fotouhi-Ardakani N, Galipeau J, Alaoui-Jamali MA: Transcriptional regulation of the TFIIH transcription repair components XPB and XPD by the hepatitis $B$ virus $x$ protein in liver cells and transgenic liver tissue. The Journal of biological chemistry 2001, 276(17):14124-14132.

19. van de Klundert MA, van Hemert FJ, Zaaijer HL, Kootstra NA: The hepatitis $B$ virus $\mathbf{x}$ protein inhibits thymine DNA glycosylase initiated base excision repair. PloS one 2012, 7(11):e48940.

20. Chappell WH, Gautam D, Ok ST, Johnson BA, Anacker DC, Moody CA: Homologous Recombination Repair Factors Rad51 and BRCA1 Are Necessary for Productive Replication of Human Papillomavirus 31. 2016, 90(5):2639-2652.

21. Savage KI, Harkin DPJTFj: BRCA1, a 'complex'protein involved in the maintenance of genomic stability. 2015, 282(4):630-646.

22. Baumann P, West SC: Heteroduplex Formation by Human Rad51 Protein: Effects of DNA Endstructure, hRP-A and hRad52. Journal of Molecular Biology 1999, 291(2):363-374.

23. Yan Q, Lan YH, Huang YX, Fan RS, Liu L, Song SP, Li YG: Hepatitis B virus replication is upregulated in proliferated peripheral blood lymphocytes. Mol Med Rep 2016, 13(4):35813587.

24. Fan YC, Sun YY, Wang N, Xiao XY, Wang K: Up-regulation of A20 gene expression in peripheral blood mononuclear cells is associated with acute-on-chronic hepatitis B liver failure. Journal of Viral Hepatitis 2016, 23(3):180-190.

25. Baumann P, West SCJTibs: Role of the human RAD51 protein in homologous recombination and double-stranded-break repair. 1998, 23(7):247-251.

26. Moynahan ME, Chiu JW, Koller BH, Jasin M: Brca1 Controls Homology-Directed DNA Repair. Molecular Cell 1999, 4(4):511-518.

27. Hosoya N, Miyagawa K: Targeting DNA damage response in cancer therapy. Cancer Science 2014, 105(4):370-388.

28. Helleday T: Homologous recombination in cancer development, treatment and development of drug resistance. Carcinogenesis 2010, 31(6):955-960.

29. Vispé S, Cazaux C, Lesca C, Defais MJNar: Overexpression of Rad51 protein stimulates homologous recombination and increases resistance of mammalian cells to ionizing radiation. 1998, 26(12):2859-2864.

30. Qiao G, Wu Y, Yang X, Zhong W, Xie D, Guan X-Y, Fischer D, Kolberg H, Kruger S, Stuerzbecher HJBjoc: High-level expression of Rad51 is an independent prognostic marker of survival in nonsmall-cell lung cancer patients. 2005, 93(1):137-143.

31. Maacke H, Opitz S, Jost K, Hamdorf W, Henning W, Krüger S, Feller AC, Lopens A, Diedrich K, Schwinger $\mathrm{E}$ et al: Over-expression of wild-type Rad51 correlates with histological grading of invasive ductal breast cancer. 2000, 88(6):907-913.

32. Hine CM, Seluanov A, Gorbunova V: Use of the Rad51 promoter for targeted anti-cancer therapy. 2008, 105(52):20810-20815.

33. Huang F, Motlekar NA, Burgwin CM, Napper AD, Diamond SL, Mazin AV: Identification of specific inhibitors of human RAD51 recombinase using high-throughput screening. ACS chemical biology 2011, 6(6):628-635. 
34. Rosen EM, Fan S, Pestell RG, Goldberg ID: BRCA1 in hormone-responsive cancers. Trends in Endocrinology \& Metabolism 2003, 14(8):378-385.

35. Wu JY, Vlastos AT, Pelte MF, Caligo MA, Bianco A, Krause KH, Laurent GJ, Irminger-Finger IJljoc: Aberrant expression of BARD1 in breast and ovarian cancers with poor prognosis. 2006, 118(5):1215-1226.

36. Wang S, Liu F, Zhu J, Chen P, Liu H, Liu Q, Han J: DNA Repair Genes ERCC1 and BRCA1 Expression in Non-Small Cell Lung Cancer Chemotherapy Drug Resistance. Med Sci Monit 2016, 22:1999-2005.

37. Wilkins T, Sams R, Carpenter MJAfp: Hepatitis B: screening, prevention, diagnosis, and treatment. 2019, 99(5):314-323.

38. El-Serag HB, Rudolph KLG: Hepatocellular carcinoma: epidemiology and molecular carcinogenesis. 2007, 132(7):2557-2576.

39. Venook AP, Papandreou C, Furuse J, DE GUEVARA LLOO: The incidence and epidemiology of hepatocellular carcinoma: a global and regional perspective. 2010, 15.

40. Luo GG, Ou J-hJ: Oncogenic viruses and cancer. Virol $\operatorname{Sin} 2015,30(2): 83-84$.

41. Hollingworth R, Grand RJ: Modulation of DNA damage and repair pathways by human tumour viruses. Viruses 2015, 7(5):2542-2591.

42. Buitrago-Molina LE, Marhenke S, Longerich T, Sharma AD, Boukouris AE, Geffers R, Guigas B, Manns MP, Vogel A: The degree of liver injury determines the role of p21 in liver regeneration and hepatocarcinogenesis in mice. Hepatology (Baltimore, Md) 2013, 58(3):1143-1152.

43. Chappell WH, Gautam D, Ok ST, Johnson BA, Anacker DC, Moody CAJJov: Homologous recombination repair factors Rad51 and BRCA1 are necessary for productive replication of human papillomavirus 31. 2016, 90(5):2639-2652.

44. Belgnaoui SM, Fryrear KA, Nyalwidhe JO, Guo X, Semmes OJJJoBC: The viral oncoprotein tax sequesters DNA damage response factors by tethering MDC1 to chromatin. 2010, 285(43):32897-32905.

45. Kudoh A, Iwahori S, Sato Y, Nakayama S, Isomura H, Murata T, Tsurumi T: Homologous Recombinational Repair Factors Are Recruited and Loaded onto the Viral DNA Genome in Epstein-Barr Virus Replication Compartments. 2009, 83(13):6641-6651.

46. Savage KI, Harkin DP: BRCA1, a 'complex' protein involved in the maintenance of genomic stability. The FEBS Journal 2015, 282(4):630-646.

47. Liao Y, Yuan S, Chen X, Zhu P, Li J, Qin L, Liao WJSr: Up-regulation of BRCA1-associated RING domain 1 promotes hepatocellular carcinoma progression by targeting Akt signaling. 2017, 7(1):1-11.

48. Juvekar A, Burga LN, Hu H, Lunsford EP, Ibrahim YH, Balmañà J, Rajendran A, Papa A, Spencer K, Lyssiotis CAJCd: Combining a PI3K inhibitor with a PARP inhibitor provides an effective therapy for BRCA1-related breast cancer. 2012, 2(11):1048-1063. 
Table 1. The list of primers employed in specific qPCRs

\begin{tabular}{|l|l|}
\hline Gene & Primers \\
\hline BRCA1 & $\begin{array}{l}\text { Forward: 5' - GCTCGTGGAAGATTTCGGTGT -3' } \\
\text { Reverse: 5' - TCATCAATCACGGACGTATCATC -3' }\end{array}$ \\
\hline Rad51 & $\begin{array}{l}\text { Forward: 5' - TCTCTGGCAGTGATGTCCTGGA -3' } \\
\text { Reverse: 5' - TAAAGGGCGGTGGCACTGTCTA -3' }\end{array}$ \\
\hline HBx & $\begin{array}{l}\text { Forward: 5' - CTTGGACTCTCAGCAATG -3' } \\
\text { Reverse: 5' - CCTACAGCCTCCTACTAC -3' }\end{array}$ \\
\hline B2MG & $\begin{array}{l}\text { Forward: 5' -CTTGTCTTTCAGCAAGGACTGG-3' } \\
\text { Reverse: 5'-CCACTTAACTATCTTGGGCTGG-3' }\end{array}$ \\
\hline
\end{tabular}


Table 2. Clinical Characteristics of healthy controls and patients

\begin{tabular}{|c|c|c|}
\hline Variables & Hepatitis B patients & Healthy controls \\
\hline $\mathbf{N}$ & 60 & 61 \\
\hline \multicolumn{3}{|l|}{ Gender } \\
\hline Male & 39 & 25 \\
\hline Female & 21 & 26 \\
\hline Age,$y$ & $48.8 \pm 10.8$ & $32.9 \pm 19.7$ \\
\hline ALT,U/L & $15.17 \pm 13.7$ & $14.9 \pm 6.3$ \\
\hline AST,U/L & $35.34 \pm 28.25$ & $26.5 \pm 9.11$ \\
\hline HBV DNA, $\log 10$ IU/ML & $4.99 \pm 1.8$ & Undetectable \\
\hline \multicolumn{3}{|l|}{ HBs Ag } \\
\hline Positive & 60 & $\mathbf{0}$ \\
\hline Negative & $\mathbf{0}$ & 61 \\
\hline \multicolumn{3}{|l|}{ HBe Ag } \\
\hline Positive & 6 & $\mathbf{0}$ \\
\hline Negative & 54 & 61 \\
\hline \multicolumn{3}{|l|}{ Anti HBc total } \\
\hline Positive & 60 & 33 \\
\hline Negative & $\mathbf{0}$ & 28 \\
\hline \multicolumn{3}{|l|}{ HBx Ag } \\
\hline Positive & 3 & $\mathbf{0}$ \\
\hline Negative & 57 & 61 \\
\hline
\end{tabular}


Table 3. Correlation between Rad51 and BRCA1 gene expression and viral load

\begin{tabular}{|c|c|c|}
\hline Spearman test & $\begin{array}{c}\text { Viral load } \\
\text { vs. } \\
\text { Rad51 }\end{array}$ & $\begin{array}{c}\text { Viral load } \\
\text { vs. } \\
\text { BRCA1 }\end{array}$ \\
\hline $\mathbf{r}$ & 0.8384 & 0.5889 \\
\hline $95 \%$ confidence interval & 0.5423 to 0.9493 & 0.06749 to 0.8577 \\
\hline P value & 0.0004 & 0.0295 \\
\hline
\end{tabular}




\section{Figure Legends}

Figure2. Comparison of BRCA1 gene expression between study groups. Statistical analysis using Mann-Whitney U. test. Results are reported median. $\left(\mathrm{P}^{*}<0.05\right)$

Figure1. Comparison of Rad51 gene expression between study groups. Statistical analysis using Mann-Whitney U. test. Results are reported median. $\left(\mathrm{P}^{* *}<0.01\right)$ 
Figure2

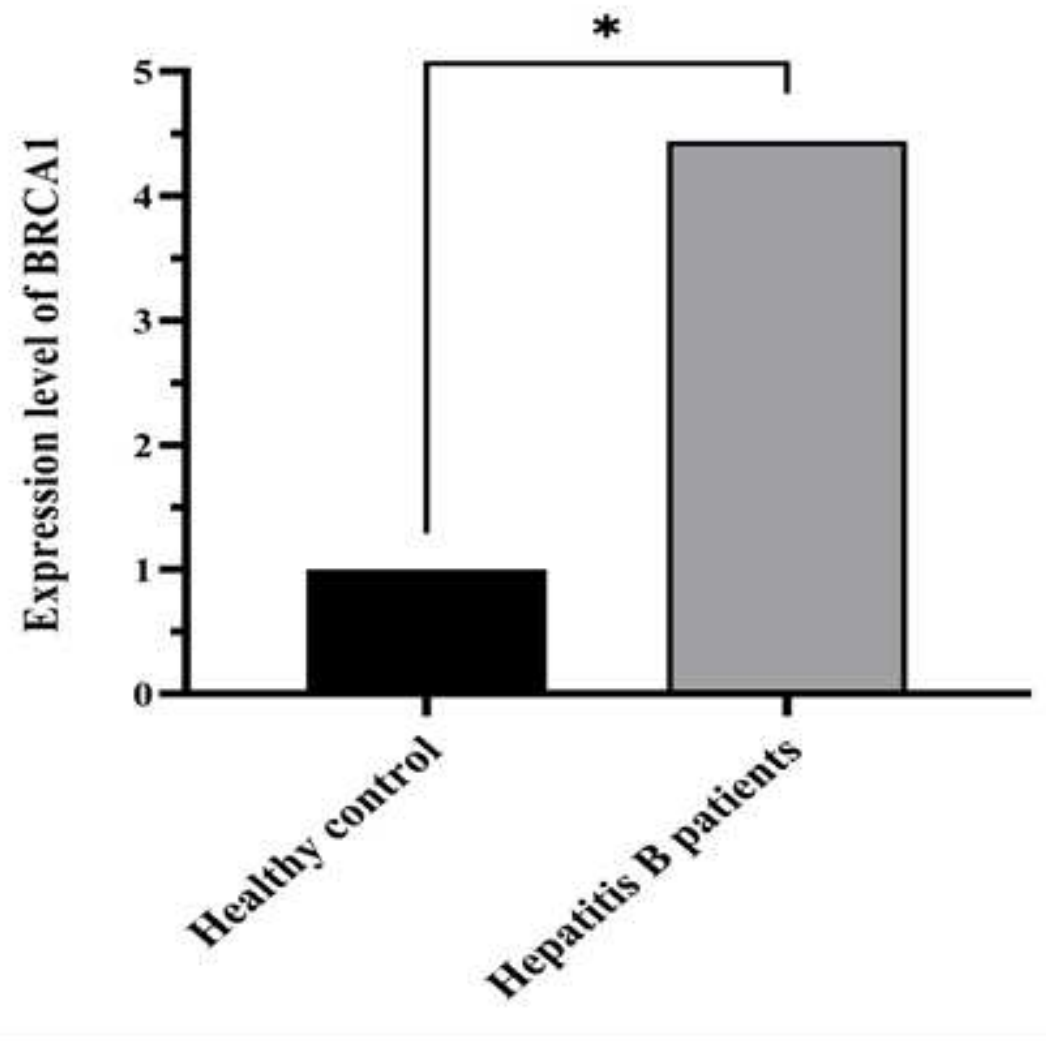


Figure1

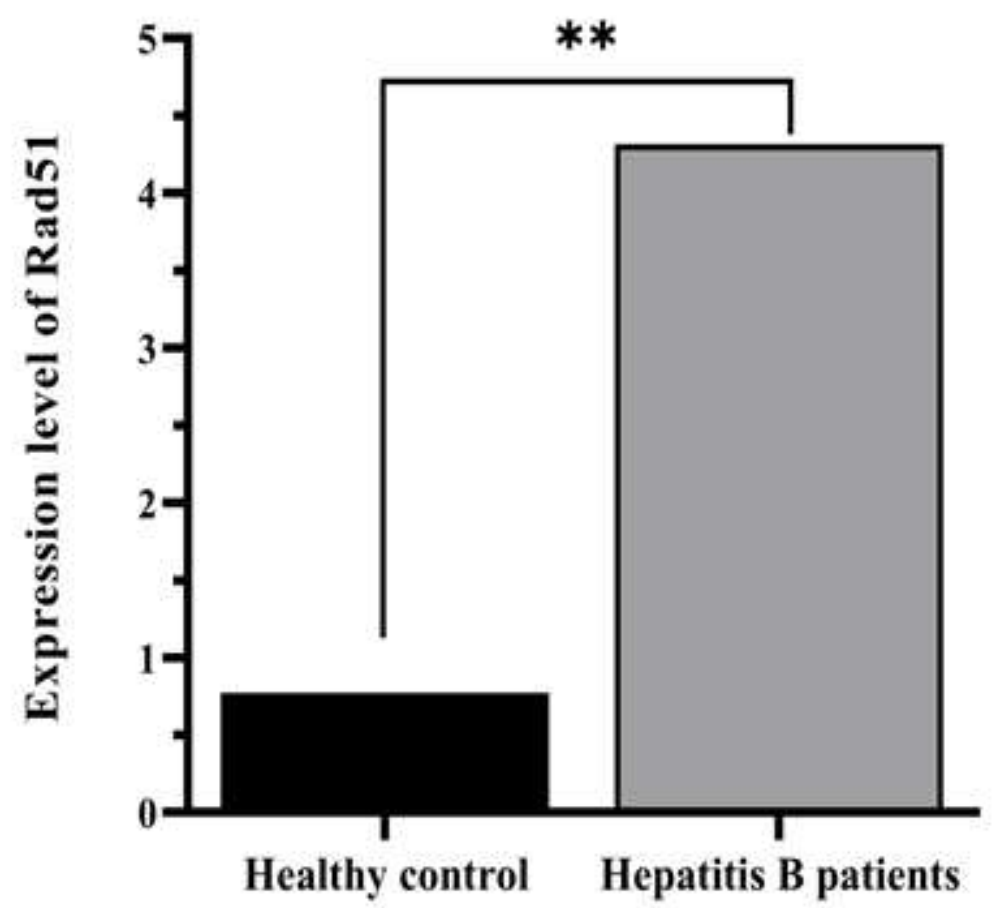


Figures

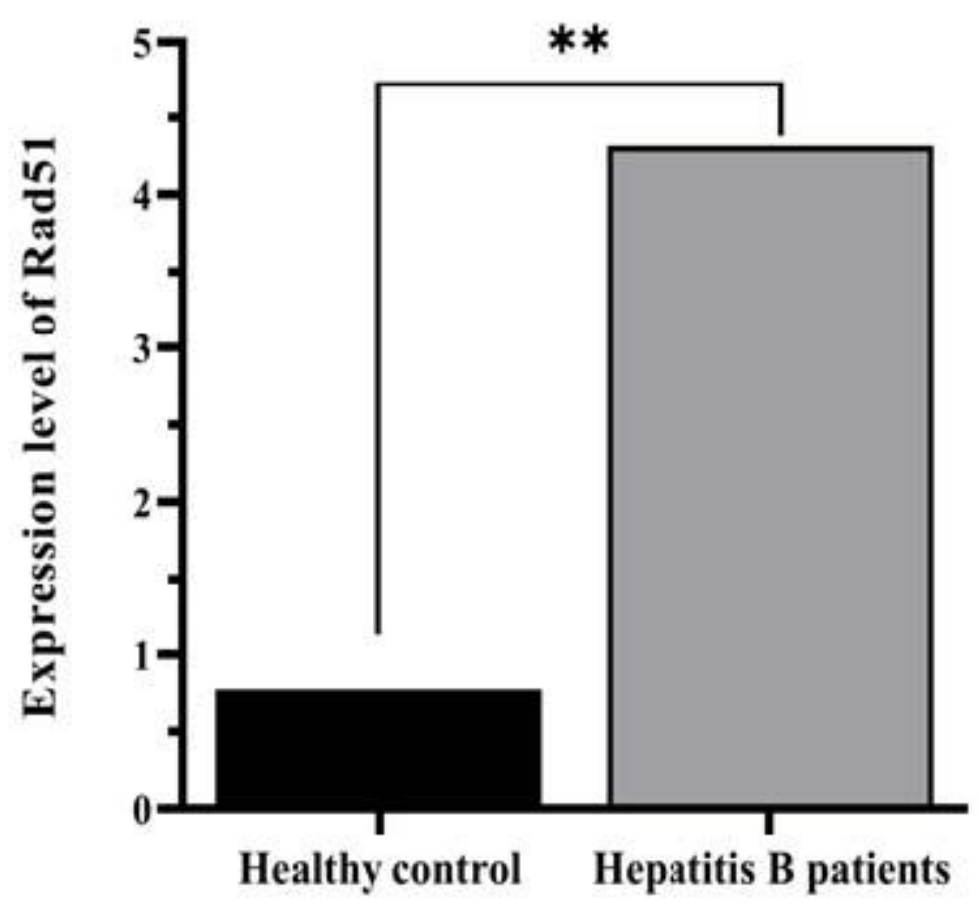

Figure 1

Comparison of Rad51 gene expression between study groups. Statistical analysis using Mann-Whitney U. test. Results are reported median. $\left(P^{\star \star}<0.01\right)$ 


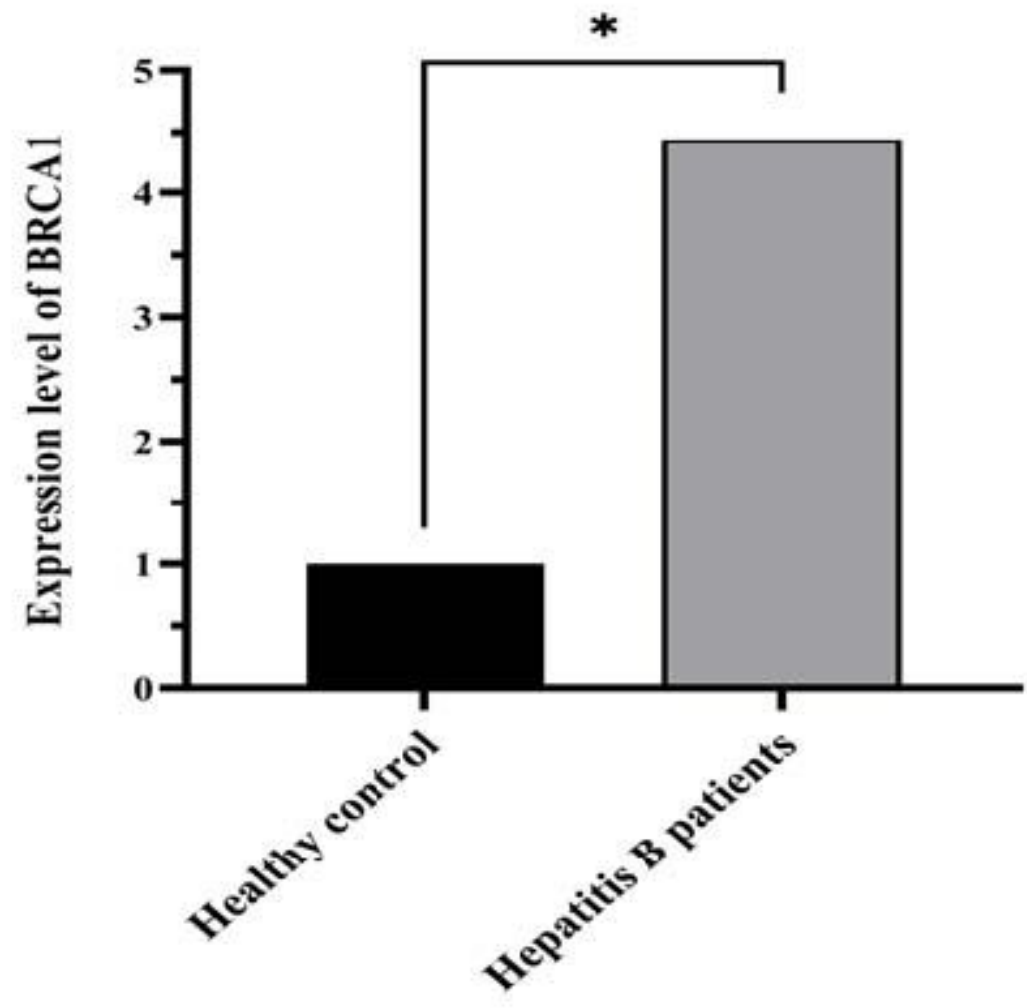

Figure 2

Comparison of BRCA1 gene expression between study groups. Statistical analysis using Mann-Whitney U. test. Results are reported median. $\left(P^{*}<0.05\right)$ 